\title{
Analysis of factors influencing molecular testing at diagnostic of colorectal cancer
}

\author{
Quentin Thiebault ${ }^{1}$, Gautier Defossez ${ }^{2,3}$, Lucie Karayan-Tapon ${ }^{4}$, Pierre Ingrand ${ }^{2,3}$, Christine Silvain ${ }^{1,5}$ \\ and David Tougeron ${ }^{1,5^{*}}$
}

\begin{abstract}
Background: The aim of the study was to evaluate the current rate of molecular testing prescription (KRAS codons $12 / 13, B R A F$ and microsatellite instability (MSI)) in newly diagnosed colorectal cancer (CRC) patients and to determine which factors influence testing.

Methods: All incident CRC cases in 2010 were identified in the Poitou-Charentes General Cancer Registry. The exhaustive molecular testing performed was accessed in the French molecular genetics platform. Factors influencing prescription were analyzed using logistic regression.

Results: Among the 1269 CRCs included in the study, KRAS, BRAF and MSI testing accounted for $35.1 \%, 10.5 \%$ and $10.9 \%$, respectively. KRAS testing was carried out in $65.5 \%$ of metastatic CRCs, and $26.1 \%$ of non-metastatic CRCs. Among metastatic CRCs, age (<60 years), site of primary tumour (left colon) and geographical area of treatment were factors related to KRAS testing. BRAF testing was contemporary to KRAS testing for $92.5 \%$ of patients. Factors related to MSI testing were age (<60 years), TNM stage (stage IV) and geographical area of treatment. Among CRC patients under 60 years old, only $37.5 \%$ had MSI testing.
\end{abstract}

Conclusion: These results underscore the need to reduce disparities in CRC molecular testing and highlight the limited application of the French guidelines, especially concerning MSI testing.

Keywords: Colorectal cancer, KRAS, Mutation, Molecular testing, BRAF, Microsatellite instability

\section{Background}

Colorectal cancer (CRC) is the third most common cancer worldwide [1]. To date, colorectal carcinogenesis has been classified in three distinct pathways: chromosomal instability (85\%), microsatellite instability (MSI) (15\%) and $\mathrm{CpG}$ island methylator phenotype (25\%). MSI is related to a deficient DNA mismatch repair (dMMR) system due to germline mutation in a MMR gene in Lynch syndrome (LS), or more commonly to an epigenetic inactivation of $M L H 1$ in sporadic cases. Approximately $45 \%$ of CRC cases have a KRAS mutation [2] and only patients with wild-type (WT) RAS metastatic CRC (mCRC) may benefit from anti-epidermal growth factor receptor monoclonal antibody therapy (anti-EGFR mAbs)

\footnotetext{
* Correspondence: davidtougeron@hotmail.fr

${ }^{1}$ Department of Gastroenterology, Poitiers University Hospital, 2 rue de la Milétrie, 86000 Poitiers Cedex, France

${ }^{5}$ Laboratory Inflammation, Tissus Epithéliaux et Cytokines, EA 4331, University of Poitiers, Poitiers, France

Full list of author information is available at the end of the article
}

$[3,4]$. A BRAF mutation (V600E) is present in approximately $12 \%$ of CRCs and confers a poor prognosis, especially in mCRCs [5-8]. In dMMR CRC, BRAF mutation is specific to a sporadic origin and eliminates a LS.

Since 2006, the French National Cancer Institute (INCa) has been supporting a national network of 28 hospital molecular genetics platforms throughout France, offering patients all essential molecular genetics techniques for all cancers. For CRC, KRAS (now complete $R A S), B R A F$ and MSI testing are routinely performed. Since 2008, KRAS testing is supposed to be performed in all mCRC cases. Since KRAS and BRAF mutations are mutually exclusive [8], $B R A F$ testing is performed only in KRAS WT tumours. In France, MSI testing is recommended in patients with a CRC at an age lower than 60 and/or if family history suggests a LS. Nevertheless, epidemiological data concerning these different testing procedures are lacking. A recent French retrospective study revealed that $81.1 \%$ of patients with a mCRC had KRAS 
testing [9]. This study has some limitations due the nonexhaustiveness of incident CRC cases included and patient recruitment based on physician willingness. The General Cancer Registry in the Poitou-Charentes region (GCRPC) covers an administrative region of 1.8 million people in south-western France (available at http://medphar.univpoitiers.fr/registre-cancers-poitou-charentes/) and has been collecting all incident cancer cases, thereby enabling exhaustive analysis of the molecular analyses (using INCa molecular cancer genetics platform) performed in all incident CRC cases. The aim of the study was to analyze routine practice of KRAS, BRAF and MSI molecular testing among all the CRC patients in Poitou-Charentes diagnosed in 2010 .

\section{Methods}

\section{Study population}

Since 2008, the GCRPC has included all incident cases of cancer, involving subjects regularly residing in the Poitou-Charentes region at the time of diagnosis, whatever the place of care. The Poitou-Charentes region comprises four departments: Charente, Charente-Maritime, DeuxSèvres and Vienne. The minimum items recorded in the GCRPC were demographic data, tumour characteristics and treatment. According to the French law the data collected from the GCRPC was approved by the CCTIRS (Comité Consultatif sur le Traitement de l'Information en matière de Recherche dans le domaine de la Santé, approval $n^{\circ} 07-374$ ) and the CNIL (Commission Nationale de l'Informatique et des Libertés, approval $\left.n^{\circ} 907,303\right)$. Using the GCRPC 1375 incident CRC patients were identified in 2010 and after exclusion of non-relevant cases, 1269 patients were included in the study (Fig. 1).

\section{Molecular testing}

In 2010, KRAS mutational status (exon 2 codons 12 and 13) was determined at the specific request of a clinician. Regarding BRAF mutational status (V600E), analysis was mostly performed by the INCa hospital molecular genetics platforms in case of $K R A S$ wild-type status. MSI was to be determined at the specific request of the clinician (suspicion of LS) or by the platforms for patients under 60 years old. All of the exhaustive molecular analyses $(n=480)$ from the different hospital molecular genetics platforms were itemized (Poitiers $(n=401)$ and other platforms $(n=79))$.

\section{Statistical analysis}

The aim of the study was to evaluate the rate of prescription of molecular testing (KRAS, BRAF and MSI) regarding guidelines applicable in 2010 to newly diagnosed CRC patients. Secondary objectives were to analyze which criteria influenced KRAS molecular testing for metastatic and non-metastatic CRC patients respectively, and which characteristics influenced MSI molecular testing for all CRC patients.

The study was conducted in accordance with the Strengthening the Reporting of Observational Studies in Epidemiology (STROBE) statement. The descriptive statistics used for quantitative parameters were mean and standard deviation; for qualitative parameters were frequency and percentage. A logistic regression was carried out on factors that could promote KRAS testing and

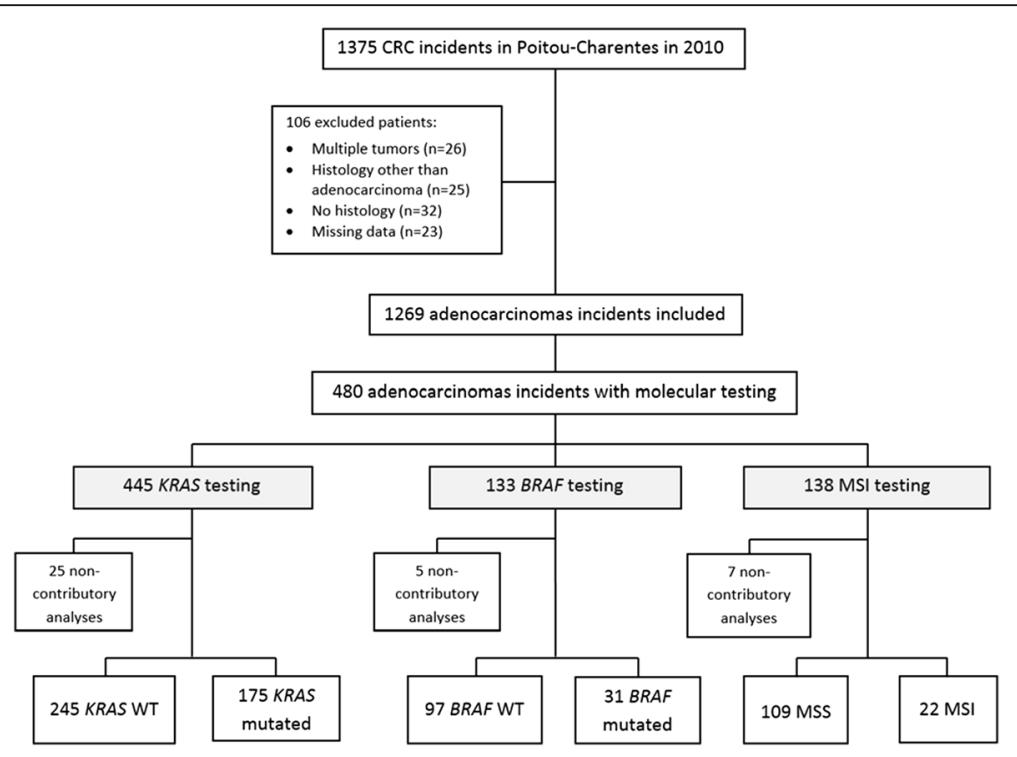

Fig. 1 Flowchart of the study. Abbreviations: CRC, colorectal cancer; WT, wild-type; MSI, microsatellite instability; MSS, microsatellite stable 
MSI testing and determined odds ratios (OR) with a 95\% confidence interval (CI). The geographical area of primary treatment was defined from the location of the center where the first treatment of CRC was performed. Status of the center was categorized as public, private or university hospital.

Statistically significant factors derived from univariate analysis $(P$ values $<0.25)$ were selected for multivariate analysis using a stepwise descending selection procedure with a significance threshold at 0.05 . Possible interactions between independent risk factors were tested by including proper cross-product terms in the regression models, and likelihood ratio tests comparing models with and without the interaction term were used to estimate the significance of the interaction. Data management and statistical analyses were performed using SAS software version 9.4 (SAS Institute, Cary, NC, USA).

\section{Results}

Population

Between January 1st and December 31st 2010, 1269 incident cases of CRC were included in the study. The agestandardized incidence rates of CRC were respectively 38.3 per 100,000 in men and 26.9 per 100,000 in women. Mean age was $71.9 \pm 11.8$ years (Table 1). At diagnosis, $22.8 \%$ of CRCs were metastatic and $77.2 \%$ were nonmetastatic.

\section{Molecular testing}

Overall, 480 CRCs (37.8\% of the cohort) had at least one molecular test (KRAS, BRAF or MSI). KRAS was mutated in $41.7 \%$ of cases $(n=175 / 420), B R A F$ mutation in $24.2 \%(n=31 / 128)$ and a dMMR phenotype was found in $16.8 \%(n=22 / 131)$. Among the 480 molecular tests in Poitou-Charentes incident cases of CRC, $83.5 \%(n=401)$

Table 1 Patient and tumour characteristics

\begin{tabular}{|c|c|c|c|}
\hline & All patients $(n=1269)$ & $\begin{array}{c}\text { Patients without molecular } \\
\text { test }^{\mathrm{a}}(n=789)\end{array}$ & $\begin{array}{l}\text { Patients with at least one } \\
\text { molecular test } \mathrm{t}^{\mathrm{a}}(n=480)\end{array}$ \\
\hline Age (years, SD) & $71.9 \pm 11.8$ & $74.4 \pm 11.3$ & $67.8 \pm 11.4$ \\
\hline \multicolumn{4}{|l|}{ Sex } \\
\hline Women & $578(45.5 \%)$ & $356(45.1 \%)$ & $222(46.3 \%)$ \\
\hline Men & $691(54.5 \%)$ & $433(54.9 \%)$ & $258(53.8 \%)$ \\
\hline \multicolumn{4}{|c|}{ Site of the primary tumour } \\
\hline Rectum & $309(24.4 \%)$ & $220(28.0 \%)$ & 89 (18.8\%) \\
\hline Right colon & 437 (34.4\%) & 268 (34.0\%) & $169(35.0 \%)$ \\
\hline Left colon & $523(41.2 \%)$ & 301 (38.0\%) & $222(46.3 \%)$ \\
\hline \multicolumn{4}{|l|}{ TNM stage } \\
\hline Stage I & $219(17.3 \%)$ & $194(24.6 \%)$ & $25(5.2 \%)$ \\
\hline Stage ॥ & $380(29.9 \%)$ & 265 (33.6\%) & 115 (24.0\%) \\
\hline Stage III & $380(29.9 \%)$ & $232(29.4 \%)$ & $148(30.8 \%)$ \\
\hline Stage IV & $290(22.8 \%)$ & 98 (12.4\%) & $192(40.0 \%)$ \\
\hline \multicolumn{4}{|c|}{ Tumour grade $(M D=173)$} \\
\hline Well & $436(39.8 \%)$ & $250(37.7 \%)$ & $186(43.3 \%)$ \\
\hline Moderate & $576(52.5 \%)$ & $369(55.4 \%)$ & $207(47.9 \%)$ \\
\hline Poor & $84(7.7 \%)$ & $46(6.9 \%)$ & $38(8.8 \%)$ \\
\hline \multicolumn{4}{|c|}{ Geographical area of primary treatment $(\mathrm{MD}=4)$} \\
\hline Charente-Maritime & $392(31.0 \%)$ & $286(36.4 \%)$ & $106(22.1 \%)$ \\
\hline Charente & $226(17.9 \%)$ & $171(21.6 \%)$ & $55(11.5 \%)$ \\
\hline Deux-Sèvres & $227(17.9 \%)$ & $110(14.1 \%)$ & $117(24.4 \%)$ \\
\hline Vienne & $301(23.8 \%)$ & $137(17.4 \%)$ & $164(34.2 \%)$ \\
\hline Outside the region & $119(9.4 \%)$ & $82(10.4 \%)$ & $37(7.7 \%)$ \\
\hline \multicolumn{4}{|c|}{ Status of the center $(M D=4)$} \\
\hline Public Hospital & $551(43.5 \%)$ & $381(48.6 \%)$ & $170(35.5 \%)$ \\
\hline Private hospital & $512(40.5 \%)$ & $292(37.2 \%)$ & $220(45.7 \%)$ \\
\hline University hospital & $202(16.0 \%)$ & $112(14.3 \%)$ & $90(18.8 \%)$ \\
\hline
\end{tabular}

$M D$ missing data, $S D$ standard deviation 
were performed in the platform of Poitiers and 16.5\% $(n=79)$ outside the region.

The average time to obtain results of molecular tests, defined by the interval between the date of histological sampling and the date of molecular test results available in the platform, was 30.6 days for KRAS testing, 36.3 days for $B R A F$ testing and 41.3 days for MSI testing.

\section{KRAS testing}

KRAS molecular testing was carried out in $35.1 \%$ ( $n=$ $445 / 1269)$, including $65.5 \%(n=190 / 290)$ metastatic and $26.1 \%(n=255 / 979)$ non-metastatic CRC patients. KRAS molecular testing was mainly requested by pathologists $(n=174,39.1 \%)$, surgeons $(n=105,23.6 \%)$ and oncologists $(n=84,18.9 \%)$ (Table 2). Among mCRC patients, $68.6 \%(n=199 / 290)$ received chemotherapy and among them 83.9\% $(n=167 / 199)$ had KRAS molecular testing.

Among overall cohort, age at diagnosis, site of primary tumor, stage at diagnosis, geographical area of primary treatment and status of the center were the factors related to KRAS testing (data not shown). Secondly, analyses of metastatic and non-metastatic CRCs were performed separately, given that KRAS testing is recommended only in cases of $\mathrm{mCRC}$.

Among mCRC patients, in multivariate analysis, age at diagnosis $(<75$ years; $p<0.0001)$, site of primary tumor (left colon; $p=0.006$ ) and geographical area of primary treatment $(p=0.01)$ were factors related to KRAS molecular testing (Table 3). All mCRC patients treated with an anti-EGFR mAbs had KRAS molecular testing $(n=42)$. Among KRAS wild-type mCRC $(n=101), 40.6 \%$ were treated with anti-EGFR mAbs. More than half of KRAS molecular testing for $\mathrm{mCRC}$ patients was requested by pathologists $(n=60,31.6 \%)$ and oncologists $(n=51,26.3 \%)$.

Among non-metastatic CRC patients, in multivariate analysis, age at diagnosis ( $<75$ years; $p<0.0001)$, site of primary tumor (right colon; $p=0.026$ ), stage at diagnosis (stage II and III; $\mathrm{p}<0.0001$ ), geographical area of primary treatment $(\mathrm{p}<0.0001)$ and status of the center (private hospital; $\mathrm{p}<0.0001)$ were factors related to KRAS molecular testing (Table 4). KRAS molecular testing for non-metastatic CRC patients was mainly

Table 2 Specialty of physicians who order molecular testing

\begin{tabular}{llll}
\hline & $\operatorname{KRAS}(n=445)$ & $\operatorname{BRAF}(n=133)$ & MSI $(n=138)$ \\
\hline Pathologists & $174(39.1 \%)$ & $38(28.6 \%)$ & $34(24.6 \%)$ \\
Surgeons & $105(23.6 \%)$ & $22(16.5 \%)$ & $21(15.2 \%)$ \\
Oncologists & $84(18.9 \%)$ & $37(27.8 \%)$ & $43(31.2 \%)$ \\
Gastroenterologists & $9(2.0 \%)$ & $1(0.7 \%)$ & $1(0.7 \%)$ \\
Others & $4(0.9 \%)$ & $7(5.3 \%)$ & $5(3.6 \%)$ \\
$\begin{array}{l}\text { Non communicated/ } \\
\text { unknown }\end{array}$ & $69(15.5 \%)$ & $28(21.1 \%)$ & $34(24.6 \%)$ \\
\hline
\end{tabular}

requested by pathologists $(n=114,44.7 \%)$ and surgeons $(n=72,28.2 \%)$.

\section{$B R A F$ testing}

$B R A F$ molecular testing was performed in $10.5 \%(n=$ $133 / 1269)$, including $18.6 \%(n=54 / 290)$ metastatic and 8.1\% $(n=79 / 979)$ non-metastatic CRC patients. BRAF molecular testing was mainly requested by pathologists $(n=38,28.6 \%)$, oncologists $(n=37,27.8 \%)$ and surgeons $(n=22,16.5 \%)$. BRAF molecular testing was contemporary to KRAS molecular testing for $92.5 \%$ of CRC patients $(n=123 / 133)$, of whom $93.5 \%(n=115 / 123)$ were KRAS WT. Among the 101 KRAS WT mCRC patients, 47.5\% $(n=48)$ had BRAF testing. Considering that BRAF testing should be performed in case of KRAS WT status, the factors associated with $B R A F$ testing were not detailed as they were in fact similar to those for KRAS testing.

\section{MSI testing}

MSI molecular testing was performed in 10.9\% $(n=138 /$ $1269), 39.4 \%(n=82 / 208)$ in patients under 60 years and $5.3 \%(n=56 / 1061)$ in patients over 60 years. MSI molecular testing was mainly requested by oncologists $(n=43$, $31.2 \%)$ and pathologists $(n=34,24.6 \%)$. Among the 138 patients with MSI testing, 58.0\% $(n=80 / 138)$ had no $B R A F$ testing. There was no significant difference in proportion of MSI testing between $B R A F$-mutated and $B R A F$ WT CRC, respectively $38.7 \%(n=12 / 31)$ and $43.3 \%(n=42 / 97)(p=0.65)$.

In multivariate analysis, age at diagnosis $(<75$ years; $p<0.0001$ ), stage at diagnosis (stage II, III and IV; $p<0.0001)$ and geographical area of primary treatment $(p<0.0001)$ were factors related to MSI testing (Table 5). Among patients under 60 years old, 39.4\% $(n=82 / 208)$ had MSI testing and $11.5 \%$ had an oncogenetic consultation $(n=24 / 208)$. Overall, among the 22 patients with dMMR CRC, we identified $6 B R A F$ wild-type CRCs (27.3\%), 9 BRAF-mutated CRCs (40.9\%) and 7 without $B R A F$ testing (31.8\%). Among patients with dMMR CRC and $B R A F$ wild-type status or no $B R A F$ testing, $61.5 \%$ had an oncogenetic consultation $(n=8 / 13)$.

\section{Discussion}

Our study is the first one to simultaneously evaluate three molecular testing procedures (KRAS, BRAF and MSI) in $\mathrm{CRC}$. Rates for these molecular testing procedures were systematically linked to age at CRC diagnosis, site of primary tumour, stage at diagnosis, geographical area of primary treatment and status of the center.

KRAS testing was performed in $35.1 \%$ of CRCs and as expected was more frequent in patients with a metastatic disease (65.5\%). Although KRAS status is required for the anti-EGFR mAbs used in mCRC, there are few data on KRAS testing rates. In a French retrospective 
Table 3 Factors influencing KRAS testing in metastatic CRC patients

\begin{tabular}{|c|c|c|c|c|c|}
\hline & & & Multivariate & & \\
\hline & $\begin{array}{l}n=190 / 290 \\
(65.5 \%)\end{array}$ & $\begin{array}{l}\text { analysis } \\
\text { P-Value }\end{array}$ & Odds ratio & $95 \% \mathrm{Cl}$ & P-Value \\
\hline Age (years) & & $<0.0001$ & & & $<0.0001$ \\
\hline$>75$ & 42 / 107 (39.3\%) & & 1 & Ref & \\
\hline $60-75$ & $97 / 126(77.0 \%)$ & & 4.72 & $2.54-8.77$ & \\
\hline$<60$ & $51 / 57(89.5 \%)$ & & 10.78 & $4.07-28.50$ & \\
\hline Sex & & 0.016 & & & 0.33 \\
\hline Women & 82 / 140 (58.6\%) & & 1 & Ref & \\
\hline Men & $108 / 150(72.0 \%)$ & & 1.34 & $0.75-2.41$ & \\
\hline Site of the primary tumour & & 0.0011 & & & 0.006 \\
\hline Rectum & 35 / 64 (54.7\%) & & 1 & Ref & \\
\hline Right colon & $51 / 90(56.7 \%)$ & & 1.44 & $0.67-3.07$ & \\
\hline Left colon & $104 / 136(76.5 \%)$ & & 3.09 & $1.48-6.45$ & \\
\hline Tumour grade $(M D=40)$ & & 0.52 & & & \\
\hline Well & $63 / 89(70.8 \%)$ & & & & \\
\hline Moderate & $83 / 131(63.4 \%)$ & & & & \\
\hline Poor & $20 / 30(66.7 \%)$ & & & & \\
\hline Geographical area of primary treatment $(\mathrm{MD}=2)$ & & 0.0001 & & & 0.010 \\
\hline Charente-Maritime & 42 / $87(48.3 \%)$ & & 1 & Ref & \\
\hline Charente & $32 / 53(60.4 \%)$ & & 1.99 & $0.89-4.46$ & \\
\hline Deux-Sèvres & $37 / 45(82.2 \%)$ & & 4.64 & $1.77-12.18$ & \\
\hline Vienne & $61 / 79(77.2 \%)$ & & 2.88 & $1.36-6.13$ & \\
\hline Outside the region & $17 / 24(70.8 \%)$ & & 2.02 & $0.67-6.12$ & \\
\hline Status of the center $(M D=2)$ & & $0.026^{\mathrm{a}}$ & & & \\
\hline Public Hospital & $60 / 83(72.3 \%)$ & & - & - & - \\
\hline Private hospital & $83 / 143(58.0 \%)$ & & & & \\
\hline University hospital & $46 / 62(74.2 \%)$ & & & & \\
\hline
\end{tabular}

95\% Cl 95\% confidence interval, MD missing data, Ref reference

${ }^{a}$ Not retained in the final multivariate model

study conducted in $201181.1 \%$ of mCRCs had KRAS testing [9] which is higher as compared our work. However, there are selection biases in Lièvre et al. study since patient recruitment was based on physician willingness. Finally, our rate is in accordance with that found in a large retrospective study published in 2011 concerning Europe, Latin America and Asia (69\%) [10]. Moreover, in our study when limited to $\mathrm{mCRC}$ patients receiving first-line chemotherapy, KRAS molecular testing rate was higher (83.9\%).

Among mCRC patients, in multivariate analysis young age at diagnosis, primary tumor located in left colon and geographical area of primary treatment were factors related to KRAS molecular testing. Frequent KRAS testing in young patients is probably explained by more "aggressive" treatment strategies in these patients, particularly anti-EGFR mAbs used. We have no explanation as to why KRAS testing was more frequent for left-sided tumors. KRAS testing was also significantly more frequent in the Vienne and Deux-Sèvres departments. In the Poitou-Charentes region there is only one university hospital located in the Vienne department. We can suppose that the higher rate of KRAS testing in Vienne department was linked to university hospital research programs and easier access to molecular testing. We observed that molecular testing procedures were mainly requested by pathologists and oncologists. An earlier request by gastroenterologists on initial biopsies should be encouraged to allow the availability of molecular tests results during the first oncological consultation in order to quickly define the optimal treatment for mCRC (RAS status and anti-EGFR treatment).

Our work showed that $26.1 \%$ of non-metastatic CRC cases had KRAS testing. The rate in the USA population is 5\% [11]. Younger age, higher stage at diagnosis, geographical area of primary treatment and status of the 
Table 4 Factors influencing KRAS testing in non-metastatic CRC patients

\begin{tabular}{|c|c|c|c|c|c|}
\hline & & & Multivariate & & \\
\hline & $\begin{array}{l}N=255 / 979 \\
(26.1 \%)\end{array}$ & $\begin{array}{l}\text { analysis } \\
\text { P-Value }\end{array}$ & Odds ratio & $95 \% \mathrm{Cl}$ & P-Value \\
\hline Age (years) & & 0.0004 & & & $<0.0001$ \\
\hline$>75$ & 90 / 446 (20.2\%) & & 1 & Ref & \\
\hline $60-75$ & $123 / 382(32.2 \%)$ & & 2.69 & $1.83-3.95$ & \\
\hline$<60$ & $42 / 151(27.8 \%)$ & & 2.26 & $1.34-3.81$ & \\
\hline Sex & & 0.25 & & & 0.15 \\
\hline Women & $133 / 541(24.6 \%)$ & & 1 & Ref & \\
\hline Men & 122 / $438(27.9 \%)$ & & 0.77 & $0.55-1.09$ & \\
\hline Site of the primary tumour & & 0.010 & & & 0.026 \\
\hline Rectum & 47 / 245 (19.2\%) & & 1 & Ref & \\
\hline Right colon & $105 / 347(30.3 \%)$ & & 1.95 & $1.20-3.16$ & \\
\hline Left colon & $103 / 387(26.6 \%)$ & & 1.47 & $0.92-2.35$ & \\
\hline TNM stage & & $<0.0001$ & & & $<0.0001$ \\
\hline 1 & $21 / 219(9.6 \%)$ & & 1 & Ref & \\
\hline$\|$ & $100 / 380(26.3 \%)$ & & 5.24 & $2.98-9.21$ & \\
\hline III & $134 / 380(35.3 \%)$ & & 9.62 & $5.47-16.90$ & \\
\hline Tumour grade $(M D=133)$ & & $0.0082^{\mathrm{a}}$ & & & \\
\hline Well & $114 / 347(32.8 \%)$ & & - & - & - \\
\hline Moderate & $103 / 445(23.2 \%)$ & & & & \\
\hline Poor & 17 / $54(31.5 \%)$ & & & & \\
\hline Geographical area of primary treatment $(\mathrm{MD}=2)$ & & $<0.0001$ & & & $<0.0001$ \\
\hline Charente-Maritime & $63 / 305$ (20.7\%) & & 1 & Ref & \\
\hline Charente & $13 / 173(7.5 \%)$ & & 0.19 & $0.10-0.37$ & \\
\hline Deux-Sèvres & $75 / 182(41.2 \%)$ & & 3.74 & $2.35-5.95$ & \\
\hline Vienne & 94 / 222 (42.3\%) & & 3.24 & $1.95-5.39$ & \\
\hline Outside the region & $10 / 95(10.5 \%)$ & & 0.36 & $0.16-0.79$ & \\
\hline Status of the center $(M D=2)$ & & $<0.0001$ & & & $<0.0001$ \\
\hline Public Hospital & 77 / 408 (18.9\%) & & 1 & Ref & \\
\hline Private hospital & 149 / $429(34.7 \%)$ & & 4.18 & $2.74-6.37$ & \\
\hline University hospital & $29 / 140(20.7 \%)$ & & 0.88 & $0.44-1.75$ & \\
\hline
\end{tabular}

95\% Cl 95\% confidence interval, NA not available, MD missing data, Ref reference ${ }^{a}$ Not retained in the final multivariate model

center were factors related to KRAS molecular testing in non-metastatic CRCs. We can suppose that it was conducted at the request of the clinician to quickly begin appropriate treatment in the event of development of metachronous metastases, especially in stage III patients. In addition, for some pathologists it was easier to address pathological samples to a molecular cancer genetics platform at the time of the first pathological examination rather than later, when the tumor blocs were archived.

To our knowledge there has been no previous study evaluating $B R A F$ testing rates in CRC cases. In our study the rate of $B R A F$ testing was $10.5 \%$ and the factors influencing $B R A F$ testing are similar to those influencing KRAS testing. The rate of BRAF-mutated CRC (24.2\%) was high as compared with the literature (approximately $12 \%)[12,13] . B R A F$ testing was mostly performed directly by molecular cancer genetic platform in patients with KRAS wild-type CRC since the two mutations are mutually exclusive. This point explains the high rate of $B R A F$-mutated CRC since only KRAS WT CRCs were analyzed for $B R A F$.

Concerning MSI testing, the rate seems low (10.8\%) but the dMMR CRC rate is in accordance with literature data $[14,15]$. To our knowledge this is the first study that analyzing factors related to MSI testing rates. Like KRAS testing, MSI testing was associated in multivariate analysis with young age, higher tumor stage and geographical area of primary treatment. French guidelines 
Table 5 Factors influencing MSI testing in all CRC patients

\begin{tabular}{|c|c|c|c|c|c|}
\hline & MSI testing & & Multivariate & & \\
\hline & $\begin{array}{l}N=138 / 1269 \\
(10.9 \%)\end{array}$ & $\begin{array}{l}\text { analysis } \\
\text { P-Value }\end{array}$ & Odds ratio & IC 95\% & P-Value \\
\hline Age (years) & & $<0.0001$ & & & $<0.0001$ \\
\hline$>75$ & 10 / $553(1.8 \%)$ & & 1 & Ref & \\
\hline $60-75$ & 46 / 508 (9.1\%) & & 5.77 & $2.80-11.89$ & \\
\hline$<60$ & 82 / 208 (39.4\%) & & 59.6 & $27.82-127.85$ & \\
\hline Sex & & 0.88 & & & 0.21 \\
\hline Women & $62 / 578(10.7 \%)$ & & 1 & Ref & \\
\hline Men & 76 / 691 (11.0\%) & & 0.75 & $0.47-1.18$ & \\
\hline Site of the primary tumour & & 0.53 & & & \\
\hline Rectum & $31 / 309$ (10.0\%) & & & & \\
\hline Right colon & 44 / 437 (10.1\%) & & & & \\
\hline Left colon & $63 / 523(12.1 \%)$ & & & & \\
\hline TNM stage & & $<0.001$ & & & 0.0001 \\
\hline 1 & $6 / 219$ (2.7\%) & & 1 & Ref & \\
\hline$\|$ & 37 / 380 (9.7\%) & & 8.62 & $3.17-23.41$ & \\
\hline III & 49 / 380 (12.9\%) & & 7.96 & $3.00-21.12$ & \\
\hline IV & $46 / 290$ (15.9\%) & & 8.79 & $3.29-23.48$ & \\
\hline Tumour grade $(M D=173)$ & & 0.34 & & & \\
\hline Well & 55 / $436(12.6 \%)$ & & & & \\
\hline Moderate & $56 / 576(9.7 \%)$ & & & & \\
\hline Poor & $9 / 84(10.7 \%)$ & & & & \\
\hline Geographical area of primary treatment $(\mathrm{MD}=4)$ & & $<0.0001$ & & & $<0.0001$ \\
\hline Charente-Maritime & $3 / 392(0.8 \%)$ & & 1 & Ref & \\
\hline Charente & $21 / 226(9.3 \%)$ & & 17.08 & $4.78-61.00$ & \\
\hline Deux-Sèvres & 19 / $227(8.4 \%)$ & & 13.98 & $3.89-50.24$ & \\
\hline Vienne & 80 / 301 (26.6\%) & & 69.59 & $20.51-236.01$ & \\
\hline Outside the region & $15 / 119(12.6 \%)$ & & 13.53 & $3.64-50.29$ & \\
\hline Status of the center $(M D=4)$ & & $<0.0001^{\mathrm{a}}$ & & & \\
\hline Public Hospital & $36 / 551(6.5 \%)$ & & - & - & - \\
\hline Private hospital & 47 / $512(9.2 \%)$ & & & & \\
\hline University hospital & 55 / $202(27.2 \%)$ & & & & \\
\hline
\end{tabular}

95\% Cl 95\% confidence interval, NA not available, MD missing data, Ref reference ${ }^{a}$ Not retained in the final multivariate model

recommended MSI testing for patients under 60 years old and/or BRAF-mutated CRC. Consequently, MSI testing was performed directly by the molecular cancer genetics platforms for patients under 60 years old and/or $B R A F$-mutated CRC when there was KRAS/BRAF testing. These points explain how it is that the factors influencing MSI testing are close to those influencing KRAS/ $B R A F$ testing.

Our study highlights the fact that guidelines for LS screening are not well-respected. Only $39.4 \%$ of CRC patients under 60 years old had MSI testing and some dMMR CRCs (31.8\%) did not have BRAF testing to identify sporadic cases. Finally, most patients with a suspicion of LS (dMMR CRC with no BRAF mutation) did not have an oncogenetic consultation (38.5\%). We were not able to determine if this was due to patient refusal or if patients had not been addressed to an oncogenetic consultant by their referring physician.

The average time to obtain results of KRAS tests in our study was 30.6 days (between histological sampling and the date when the molecular test results were available in the platform). Lièvre et al., calculated the median delay between physician prescription and reception of the results as $23.6 \pm 28.2$ days, a delay somewhat shorter because measured differently [9]. In addition, in contrast to the Lièvre et al. study, our study is reflective of real 
life and exhaustive. To our knowledge, no previous study evaluated delays in $B R A F$ and MSI testing.

The main strength of our study resides in the crossing of two reliable and exhaustive data banks, GCRPC and INCa molecular cancer genetics platforms. If none of the previous studies evaluating KRAS testing are as exhaustive, it is because they were based on incomplete database and/or on questionnaires sent to volunteer physicians. The main limitation of our work is the difficulty in extrapolating its results to other countries since CRC molecular tests are dependent on physicians' and pathologists' clinical practices. It is noteworthy that we accessed the molecular testing rates in 2010 since there is a delay of at least 2 years before obtaining high-quality CRC data from the GCRPC, a delay justified by the data collection process and the application of standards and requirements during case registration. Moreover, it is challenging to retrieve reliable and retrospective information on life-style and family history, but it would be interesting to complete this evaluation by including CCR risk factors which probably influences the choice of the clinician for ordering molecular testing. Finally, factors influencing these molecular testing procedures are relevant for countries which already performed these tests but also those who are implementing these tests in order to allow an optimal use, especially RAS testing for antiEGFR therapy used in mCRC.

\section{Conclusion}

To conclude, this study is the first to provide a robust and exhaustive overview of molecular testing in CRC. As expected, we note a high level of KRAS testing in mCRC but also significant level in stage III CRC, which was probably undertaken in order to have KRAS results for patients with a high risk of disease recurrence. Moreover, MSI testing rate is low and not in accordance with French guidelines, which recommend systematic testing before the age of 60. In addition, these results highlighted on which factors it is possible to act to improve the molecular testing procedures essential to management of CRC patients, particularly MSI testing.

\section{Abbreviations}

Cl: Confidence interval; CRC: Colorectal cancer; dMMR: Deficient DNA mismatch repair; GCRPC: General cancer registry in the poitou-charentes region; LS: Lynch syndrome; MSI: Microsatellite instability; OR: Odds ratios; WT: Wild-type

\section{Acknowledgments}

The authors wish to thank J. Arsham, an American translator, for having reviewed and revised the original English-language text. The authors thank $\mathrm{V}$. Le Berre, a research secretary, for her help in editing and formatting the manuscript.

\section{Funding}

This work was supported in part by the Ligue contre le Cancer of Vienne, Deux-Sèvres, Charente and Charente-Maritime departments and the "Sport et Collection" foundations for the molecular MSI testing.

\section{Availability of data and materials}

The datasets used and/or analyzed during the current study are available from the corresponding author on reasonable request.

\section{Authors' contributions}

Conception and design of the study: QT, GD, LK, PI, CS, DT. Data analysis and interpretation: QT, GD, LK, PI, CS, DT. Data acquisition, statistical analysis and writing the manuscript: QT, GD, DT. Final approval of the manuscript: $Q T, G D$, LK, PI, CS, DT. All authors read and approved the final manuscript.

\section{Ethics approval and consent to participate}

This study was approved by the French regulatory authorities (the "Comité Consultatif sur le Traitement de l'Information en matière de Recherche dans le Domaine de la Santé" and the "Commission Nationale Informatique et Libertés", authorisation number 907303). According to French law, patients were informed of their data registration and given the right to deny access or to rectify their personal data. The informed consent was verbal as no biomedical intervention was performed.

Consent for publication

Not applicable.

\section{Competing interests}

The authors declare that they have no competing interests.

\section{Publisher's Note}

Springer Nature remains neutral with regard to jurisdictional claims in published maps and institutional affiliations.

\section{Author details}

${ }^{1}$ Department of Gastroenterology, Poitiers University Hospital, 2 rue de la Milétrie, 86000 Poitiers Cedex, France. ${ }^{2}$ Poitou-Charentes General Cancer Registry, Poitiers University Hospital, University of Poitiers, Poitiers, France. ${ }^{3}$ INSERM, CIC 1402, Poitiers, France. ${ }^{4}$ Department of Cancer Biology, Poitiers University Hospital, Poitiers, France. ${ }^{5}$ Laboratory Inflammation, Tissus Epithéliaux et Cytokines, EA 4331, University of Poitiers, Poitiers, France.

Received: 14 June 2017 Accepted: 6 November 2017

Published online: 14 November 2017

\section{References}

1. Globocan. Estimated cancer incidence, mortality and prevalence worldwide in 2012. Lyon: International Agency for Research on Cancer; 2012. Available from: http://globocan.iarc.fr

2. Bos JL. The ras gene family and human carcinogenesis. Mutat Res. 1989;195:255-71.

3. Di Fiore F, Blanchard F, Charbonnier F, Le Pessot F, Lamy A, Galais MP, et al. Clinical relevance of KRAS mutation detection in metastatic colorectal cancer treated by Cetuximab plus chemotherapy. Br J Cancer. 2007:96:1166-9.

4. Bokemeyer C, Bondarenko I, Hartmann JT, de Braud F, Schuch G, Zubel A, et al. Efficacy according to biomarker status of cetuximab plus FOLFOX-4 as first-line treatment for metastatic colorectal cancer: the OPUS study. Ann Onco. 2011;22:1535-46.

5. Cantwell-Dorris ER, O'Leary JJ, Sheils OM. BRAFV600E: implications for carcinogenesis and molecular therapy. Mol Cancer Ther. 2011;10:385-94.

6. Weisenberger DJ, Siegmund KD, Campan M, Young J, Long TI, Faasse MA, et al. CpG island methylator phenotype underlies sporadic microsatellite instability and is tightly associated with BRAF mutation in colorectal cancer. Nat Genet. 2006:38:787-93

7. Li WQ, Kawakami K, Ruszkiewicz A, Bennett G, Moore J, lacopetta B. BRAF mutations are associated with distinctive clinical, pathological and molecular features of colorectal cancer independently of microsatellite instability status. Mol Cancer. 2006;5:2.

8. Rajagopalan H, Bardelli A, Lengauer C, Kinzler KW, Vogelstein B, Velculescu VE. Tumorigenesis: RAF/RAS oncogenes and mismatch-repair status. Nature. 2002;418:934.

9. Lièvre A, Artru P, Guiu M, Laurent-Puig P, Merlin JL, Sabourin JC, et al. The KRAS mutation detection within the initial management of patients with metastatic colorectal cancer: a status report in France in 2011. Eur J Cancer. 2013;49:2126-33. 
10. Ciardiello F, Tejpar S, Normanno N, Mercadante D, Teague T, Wohlschlegel B, et al. Uptake of KRAS mutation testing in patients with metastatic colorectal cancer in Europe, Latin America and Asia. Target Oncol. 2011;6:133-45.

11. Charlton ME, Karlitz JJ, Schlichting JA, Chen WW, Lynch CF. Factors associated with guideline-recommended KRAS testing in colorectal cancer patients: a population-based study. Am J Clin Oncol. 2017:40(5):498-506.

12. Baldus SE, Schaefer KL, Engers R, Hartleb D, Stoecklein NH, Gabbert HE. Prevalence and heterogeneity of KRAS, BRAF, and PIK3CA mutations in primary colorectal adenocarcinomas and their corresponding metastases. Clin Cancer Res. 2010;16:790-9.

13. Tol J, Nagtegaal ID, Punt CJ. BRAF mutation in metastatic colorectal cancer. N Engl J Med. 2009;361:98-9.

14. Jung SB, Lee HI, Oh HK, Shin $\mathrm{H}$, Jeon CH. Clinico-pathologic parameters for prediction of microsatellite instability in colorectal cancer. Cancer Res Treat. 2012:44:179-86.

15. Sinicrope FA, Rego RL, Halling KC, Foster N, Sargent DJ, La Plant B, et al. Prognostic impact of microsatellite instability and DNA ploidy in human colon carcinoma patients. Gastroenterology. 2006;131:729-37.

Submit your next manuscript to BioMed Central and we will help you at every step:

- We accept pre-submission inquiries

- Our selector tool helps you to find the most relevant journal

- We provide round the clock customer support

- Convenient online submission

- Thorough peer review

- Inclusion in PubMed and all major indexing services

- Maximum visibility for your research

Submit your manuscript at www.biomedcentral.com/submit
Biomed Central 